\title{
A Monte Carlo Filtering Application for Systematic Sensitivity Analysis of Computable General Equilibrium Results
}

\author{
Sébastien Mary ${ }^{1}$, Euan Phimister $^{2}$, Deborah Roberts ${ }^{3,4}$, Fabien Santini ${ }^{5}$ \\ ${ }^{1}$ DePaul University, Department of Economics, Loop Campus, Chicago, USA \\ ${ }^{2}$ University of Aberdeen Business School, Aberdeen, United Kingdom \\ ${ }^{3}$ University of Aberdeen Business School, Aberdeen, United Kingdom \\ ${ }^{4}$ The James Hutton Institute, Craigiebuckler, Aberdeen, United Kingdom \\ ${ }^{5}$ European Commission, DG AGRI, Brussels, Belgium
}

\begin{abstract}
Parameter uncertainty has fuelled criticisms on the robustness of results from computable general equilibrium models. This has led to the development of alternative sensitivity analysis approaches. Researchers have used Monte Carlo analysis for systematic sensitivity analysis because of its flexibility. But Monte Carlo analysis may yield biased simulation results. Gaussian quadratures have also been widely applied, although they can be difficult to apply in practice. This paper applies an alternative approach to systematic sensitivity analysis, Monte Carlo filtering and examines how its results compare to both Monte Carlo and Gaussian quadrature approaches. It does so via an application to rural development policies in Aberdeenshire, Scotland. We find that Monte Carlo filtering outperforms the conventional Monte Carlo approach and is a viable alternative when a Gaussian quadrature approach cannot be applied or is too complex to implement.
\end{abstract}

KEYWORDS: Monte Carlo Filtering, Systematic Sensitivity Analysis, Computable General Equilibrium model, Common Agricultural Policy, Pillar 2, rural development.

JEL: Q18, D58, R11 


\section{Introduction}

Computable general equilibrium (CGE) modeling is increasingly used for applied policy analysis, including the assessment of energy (e.g., Phimister and Roberts, 2012), agricultural (e.g., Psaltopoulos et al., 2011) or structural policies (e.g., Lima and Cardenete, 2007). While they have several advantages, CGE models suffer from uncertainty in the choice of model elasticities - i.e., parameters may be known imprecisely. A corollary issue is that the choice of elasticities can be critical to model outcomes. The problem is worse at a regional level, which typically suffers from less reliable data (Partridge and Rickman, 1998). This particularly affects empirical studies on agricultural or rural development policies, in which the modeling of regional or subregional features (e.g., differences between urban and rural areas) is often required. The existence of parametric uncertainty has thus fuelled criticisms on the robustness of CGE results and has led to the development of alternative approaches to sensitivity analyses.

Early studies applied sensitivity analyses in a limited fashion, at most changing a (single) few elasticities to evaluate simulation robustness. But there are several issues with such limited analyses, especially in relation with the interpretation and the robustness of results (Wiggle, 1991). Increases in computing power over the last 20 years has enabled increasing application of Monte Carlo (MC) analysis for the systematic sensitivity analysis (SSA) of CGE models. Its flexibility and ease of implementation have made it an attractive approach. Still, the "curse of dimensionality" remains an issue when considering multiple integrals with the approximation error of MC increasing as the number of parameters under consideration increases. For example, DeVuyst and Preckel (2007) show that MC approximation error can still be relatively large for simple functions with a small number of variables, even when numerous trials are performed. Similarly, using a simple benchmark CGE model, Hermeling and Mennel (2008) show that the convergence of standard MC results can be poor in multidimensional SSA even for relatively large sample sizes.

Gaussian quadrature (GQ) methods are traditionally used to address the dimensionality issues (Artavia et al., 2015; Villoria and Preckel, 2017; Chatzivasileiadis, 2018), some of which are now included in standard software packages (e.g., GEMPACK). This involves approximating the moments of the joint distribution of the parameters using a discrete joint probability distribution evaluated over a finite number of points (Arndt, 1996; DeVuyst and Preckel, 1997). For example, if the parameters are assumed to be jointly independently and symmetrically distributed, then it is possible to apply the Stroud (1957) points and approximate the first and second moments of the joint distribution of the parameters using a heavily reduced number of model runs.

But if more general distributions are considered, e.g., nonsymmetric distributions, such methods are much more difficult to apply in practical modelling (DeVuyst and Preckel, 2007) and the restricted sampling in GQ may not be desired in some applications (e.g., modelling of thresholds, tariffs, or quotas). For example, although the degree of GQ approximation error is likely to be small when the underlying CGE model is well approximated by a smooth polynomial, in models where nonsmooth responses are included, e.g., regime switches, the restricted sampling in GQ may yield larger approximation errors that are difficult to evaluate (Ginsburgh and Keyzer, 1997, Preckel et al., 2011). Also, the GQ approach drops information on the shape of the distribution, its higher-order moments, and its range, all of which can be of interest to researchers when they study shocks with asymmetric impacts (Chatzivasileidis, 2018). 
This paper develops and applies an alternative approach to SSA, MC filtering (MCF) and highlights potential trade-offs in the choice of an SSA approach for CGE models as extolled in recent literature on SSA (e.g., Villoria and Preckel, 2017; Chatzivasileiadis, 2018). The MCF approach both identifies the most influential parameters in the model in terms of their influence on model outcomes and provides robust policy impact estimates. The approach has the flexibility of the MC approach in that it easily deals with nonsymmetric and general non-independent distributions, unlike GQ; at the same time, it reduces the MC approximation error by limiting the dimensionality of the problem under study and preserves the distributional information.

MCF is a two-step procedure in which a nonparametric approach is first used to identify key elasticities in the CGE model and then MC sensitivity analysis is implemented focussing on only the most important model parameters. The approach breaks down parametric uncertainty systematically; it thus allows model parameters to be classified according to their relative importance in determining model results. In addition, by identifying those parameters that are most important in determining model results, it provides useful information about model properties that is helpful in understanding the model's behaviour. Parametric methods (e.g., regression-based approach) have been used analogously to reveal the link between inputs, such as elasticities, and model outputs in a CGE model (see, e.g., Belgodère and Vellutini, 2011; Anthoff and Tol, 2013; Chatzivasileiadis et al., 2017). While these may provide reasonable local approximations, the assumption of linearity and monotonicity in the relationships is unlikely to hold generally except for a small number of parameters (Saltelli et al., 2008). Hence the nonparametric MCF technique is less restrictive than regression-based approaches, while it also provides a method that identifies key parameters which are integrated within the SSA.

Herein we illustrate the proposed MCF approach and examine how its results compare to the MC and GQ approaches, in relation to an analysis of the impact of EU rural development policies on the Nomenclature d'Unités Territoriales Statistiques (NUTS) 3 region of Aberdeen City and Aberdeenshire. The particular focus is on Pillar 2 Rural development measures, which aim to support the growth and diversification of rural areas and to facilitate the provision of environmental public goods. ${ }^{1}$

There is a vast literature on the evaluation of rural development policy impacts, using regional input-output (e.g., Mattas and Shrestha, 1991) and social accounting matrix (SAM) models (e.g. Roberts, 1995). Such models are typically based on strong behavioural assumptions and often result in the generation of upper-bound estimates of the magnitude of impacts (Miller and Blair, 2009; Kilkenny, 2008). CGE models address these limitations and have been used to study EU agricultural policies at national level (e.g., Bascou et al., 2006; Gohin and Latruffe, 2006; Törmä and Lehtonen, 2009). Recent CGE studies have investigated the impacts of changing the structure of CAP Pillar 1 and 2 at a (much) more disaggregated level of analysis, allowing for a split between rural and urban areas at regional level (Psaltopoulos et al., 2011; Hyytiä, 2011; Espinosa et al., 2013). In line with these studies, we examine the impacts of a redistribution of CAP Pillar 2 funds between its axes by using a bi-regional CGE model that bifurcates urban and rural parts of the region. This enables an exploration of the impacts on the rural economy.

The remainder of the text is organised as follows. Section 2 presents approaches to systematic sensitivity analyses. Section 3 details the construction of the Social Accounting Matrix

\footnotetext{
${ }^{1}$ Pillar 1 is generally aimed at supporting producers through direct support and market measures.
} 
and policy simulations. Section 4 identifies the key elasticities in the CGE model. Section 5 examines the simulation results. Section 6 concludes.

\section{Systematic Sensitivity analyses in CGE models}

Following Arndt (1996), a CGE model can be expressed as follows:

$$
G(\mathbf{x}, \boldsymbol{\delta})=0
$$

where $\mathbf{x}$ represents a vector of endogenous variables and $\boldsymbol{\delta}$ a vector of exogenous variables (e.g., elasticities, parameters). Given the existence of a solution to Equation (1), define the vector of results of interest $\mathbf{h}(\boldsymbol{\delta})$; as the estimates in $\boldsymbol{\delta}$ are random, we can rewrite the calculation of the mean results and of the variance of results, respectively as:

$$
\begin{gathered}
E[\mathbf{h}(\boldsymbol{\delta})]=\int_{\Omega} \mathbf{h}(\boldsymbol{\delta}) g(\boldsymbol{\delta}) d \boldsymbol{\delta} \\
E\left[(\mathbf{h}(\boldsymbol{\delta})-E[\mathbf{h}(\boldsymbol{\delta})])^{2}\right]=\int_{\Omega}(\mathbf{h}(\boldsymbol{\delta})-E[\mathbf{h}(\boldsymbol{\delta})])^{2} g(\boldsymbol{\delta}) d \boldsymbol{\delta}
\end{gathered}
$$

where $g(\boldsymbol{\delta})$ is the multivariate density function and $\Omega$ is the region of integration.

CGE model simulations can therefore be viewed as numerical integration problems. This approach generates more accurate results ${ }^{2}$ and provides more information about the simulation results (Arndt, 1996). In particular, MC or GQ methods can be used to calculate the mean values in Equation (2), from which standard deviations can easily be computed.

\subsection{Monte Carlo approach}

To simply the exposition, let's assume the following univariate integration problem:

$$
\int_{a}^{b} f(\delta) g(\delta) d \delta
$$

where $g(\delta)$ is the density function. Typically, in CGE models, the integrand cannot be analytically evaluated, so we must numerically approximate the integral:

$$
\sum_{j=1}^{\mathrm{J}} w_{j} f\left(\delta^{j}\right)
$$

where J represents the number of evaluations of $f($.$) and w_{j}$ the weight attached to each evaluation.

The Monte Carlo is a special case in which J (pseudo) random numbers are generated from a distribution $g(\delta)$ in the interval $[a, b]$, the integrand is evaluated J times, and the weight $1 / \mathrm{J}$ is attached to the results of each evaluation. The approximation will be good under mild conditions on the integrand as long as J is large. For general guidance on how large J should be, Haber (1970) recommends between 40,000 and 100,000 evaluations, though his recommendation for Monte Carlo simulations is independent on the number of stochastic variables (Villoria and Preckel, 2017). ${ }^{3}$

\footnotetext{
${ }^{2}$ Because it is unlikely that linear approximations to $\mathbf{h}(\boldsymbol{\delta})$ are appropriate in a CGE model, $E[\mathbf{h}(\boldsymbol{\delta})]$ is not a good approximation to the integral in Equation (2) and therefore employing mean values for exogenous variables will traditionally lead to significant approximation error in the estimate of the mean of results.

3 The convergence has to be discussed with respect to particular indicators. For instance, in our application, the traditional Monte Carlo approach requires more than 3,000 simulations to converge towards the mean agricultural GDP effect (we do not report these results), but needs 5,000 simulations to be within acceptable error margin (i.e.
} 
While this is feasible in the univariate case given the development of computing in the last decades, this remains challenging in the multivariate case, where typically with large CGE models it can take several minutes to a model solution. Hence often researchers have used the MC approach but with a relatively small number of model evaluations, which affects the accuracy of the results. This is the curse of dimensionality that limits the applicability of MC methods (Wiggle, 1991).

\subsection{Gaussian Quadratures}

To solve this issue, researchers have used quadratures, which are formulas producing a set of chosen points within the interval $[a, b]$, and associated weights $w$ to evaluate the integrand with a limited number of evaluations. Typically, GQs have been applied to CGE models and have been more efficient than other approaches (DeVuyst and Preckel, 1997).

For the integration problem in Equation (5), a GQ of order $d$ solves the system of equations:

$$
\sum_{j=1}^{\mathrm{J}} w_{j}\left(\delta^{j}\right)^{S}=\int_{a}^{b}(\boldsymbol{\delta})^{S} g(\boldsymbol{\delta}) d \boldsymbol{\delta}, \quad s=0,1,2, \ldots, d
$$

This can be extended to the multivariate case where $\boldsymbol{\delta}$ is now a vector of size $\mathrm{M}$, that is, $\boldsymbol{\delta}_{\mathbf{m}}$ where $\mathrm{m}=1, \ldots, \mathrm{M}$, and integration occurs over a region $\Omega$ :

$$
\sum_{j=1}^{\mathrm{J}} w_{j} \prod_{m=1}^{M}\left(\boldsymbol{\delta}_{\mathbf{m}}\right)^{l_{m}}=\int_{\Omega}\left[\prod_{m=1}^{M}\left(\boldsymbol{\delta}_{\mathbf{m}}\right)^{l_{m}}\right] g(\boldsymbol{\delta}) d \boldsymbol{\delta}
$$

for all combinations of nonnegative integers $l_{m}$ and $\sum_{m=1}^{M} l_{m} \leq d$.

Conceptually, a J-point univariate GQ integrates all polynomials of degree less than $2 \mathrm{~J}$ exactly. In contrast, while Monte Carlo integration is easy to implement, it is subject to a sampling error so no deterministic error bound can be evaluated. In the GQ case, if the integrand is smooth (as is likely to be the case in the standard CGE models), the error of approximation declines at an exponential rate as the order of the GQ increases. For the MC case, the convergence of the probabilistic error as the sample size $\mathrm{N}$ increases is seen to be slower (Harber, 1970).

Stroud (1957) developed a method for drawing a cubic GQ for symmetric distributions. For a model with $n$ random exogenous variables, the method permits systematic sensitivity analyses with respect to these random variables using only $2 n$ points (or model solves).

Let $\Gamma_{k}\left(\gamma_{k 1}, \gamma_{k 2}, \ldots, \gamma_{k n}\right)$ the $k^{t h}$ quadrature point $(k=1,2, \ldots, 2 n)$. With $r=1,2, \ldots, \underline{n / 2}$ where $n / 2$ denotes the greatest integer not exceeding $n / 2$, the points may be derived by: ${ }^{4}$

$$
\gamma_{2 r-1}=\sqrt{2} \cos \left(\frac{(2 r-1) k \pi}{n}\right) \quad \gamma_{2 r}=\sqrt{2} \sin \left(\frac{(2 r-1) k \pi}{n}\right)
$$

Stroud proved that the points derived from the formula above satisfy the conditions in Equation (7). If results can be well approximated by a cubic polynomial, GQ analyses will be accurate despite the limited number of model evaluations (Arndt and Hertel, 1997).

0.01). Meanwhile, other variables of interest may still have higher error margins. More importantly, the sign for the total GDP effect has yet to converge towards the mean (negative) effect even after 5,000 MC simulations.

${ }^{4}$ Since weights $w_{k}$ are equal and must sum to 1 , then $w_{k}=\frac{1}{2 n}$. 
While the GQ approach provides an easy way to implement SSA, it may not always be practical or desirable; if more general distributions are considered e.g. non-symmetric distributions, these methods are significantly more difficult to apply in practical modelling (DeVuyst and Preckel, 2007; Arndt, 1996), while the restricted sampling in GQ may not be desirable in some applications (Preckel et al., 2011).

\subsection{Monte Carlo Filtering}

In large economic models, it is important to recognize that just a few parameters are likely to be influential and the rest will be less so (Saltelli et al., 2008). From this, the strategy behind the MCF to reduce the MC bias is not to choose a smaller set of particular points at which the model is evaluated, but rather to choose a smaller set of exogenous parameters on which to evaluate the model. In that sense, the approach eliminates irrelevant variation emanating from unimportant parameters, while preserving all the advantages of an MC-based approach.

The basic idea of MCF is to divide the output sample obtained from an MC analysis in two subsets according to a base criterion and test whether the inputs associated to those subsets are different. Consider the samples obtained via MC simulations for a given parameter $\Delta$ and an output variable $X$, respectively $\left(\delta_{1}, \delta_{2}, \ldots, \delta_{n}\right)$ and $\left(x_{1}, x_{2}, \ldots, x_{n}\right)$. Note that before using the MCF approach, it is necessary to sort the output sample $\left(x^{(1)}, x^{(2)}, \ldots, x^{(n)}\right)$ and re-order the corresponding input sample $\left(\delta^{(1)}, \delta^{(2)}, \ldots, \delta^{(n)}\right)$. The first step is then to divide the output sample based on a criterion $x^{(c)}-$ and divide it two corresponding subsamples $\left(x^{(1)}, x^{(2)}, \ldots, x^{(c)}\right)$ and $\left(x^{(c+1)}, x^{(c+2)}, \ldots, x^{(n)}\right)$. Then, the input sample is divided accordingly into two corresponding subsamples $\left(\delta^{(1)}, \delta^{(2)}, \ldots, \delta^{(c)}\right)$ and $\left(\gamma^{(c+1)}, \gamma^{(c+2)}, \ldots, \gamma^{(n)}\right)$.

These latter subsamples are used to perform the two-sample Kolmogorov-Smirnov (KS) test, ${ }^{5}$ which considers whether both subsamples are statistically different and therefore if the input parameter is either important or not. With the $p$-values associated with the Kolmogorov-Smirnov tests, it is possible to classify the influence of the parameters given the following decision rule (Saltelli et al., 2004):

i. If the $p$-value is lower than 0.01 , the input parameter is critical (or highly important);

ii. If the $p$-value is between 0.01 and 0.1 , the input parameter is important;

iii. If the $p$-value is greater than 0.1 , the input parameter is un-important.

The MCF has the same advantage as the MC approach in that it is simple and can accommodate different types of distributions easily. More fundamentally, it reduces the MC bias in large models as it reduces the curse of dimensionality by limiting the simulations to a smaller

\footnotetext{
${ }^{5}$ The KS test is conventionally used to assess the hypothesis that two samples were drawn from different populations (Neuhauser, Welz and Ruxton, 2017). Unlike the parametric $t$-test or the Wilcoxon-Mann-Whitney (or Mann-Whitney $U$ ) test, which test for differences in the location of two samples (differences in means or differences in average ranks respectively), the KS test is also sensitive to differences in the general shapes of the distributions in the two samples (i.e., to differences in dispersion, skewness, etc.). The Epps-Singleton test does not compare distributions directly but compare the empirical characteristic functions. This test has arguably similar power than the KS test though this has been subject to recent debate (Neuhauser, Welz and Ruxton, 2017). Finally, the KS test is easy to interpret and implement. We follow Saltelli et al. $(2004 ; 2008)$ in the use of the KS test.
} 
set of parameters. From an economic standpoint, it also helps providing information about the model and simulation results that neither simple MC analysis nor GQ provide.

The approach has, however, a few drawbacks. In particular, while the Smirnov test is sufficient to conclude that a parameter is important, it does not provide a necessary condition for importance, i.e., its insignificance does not mean that a parameter is actually un-influential (Saltelli et al., 2004). Also, the approach does not account for interactions between parameters (Saltelli et al., 2008). Finally, it requires first running a MC simulation, then performing the KS tests before eventually re-running the model using the set of important parameters for a J number of times; overall, the approach therefore may be time-consuming.

Despite these drawbacks, the KS is superior to parametric approaches in that it does not rely on either linearity or monotonicity. As explained in the introduction, both assumptions are unlikely to hold for a large number of parameters and parametric approaches based on these assumptions may result in misleading conclusions about the influence of parameters (Saltelli et al., 2004; 2008). Hence the nonparametric MCF technique is less restrictive than regression-based approaches.

We originally tested regression-based approaches in an earlier version of the working paper. We found that the $R^{2}$ associated with the linear regression suggested nonlinearies were substantial. Also, collinearity issues affect this regression and several elasticities are dropped. Then, we tested the use of a rank regression. The effect of studying ranks instead of raw values is such that all monotonic input-output relationships are linearized (Storlie and Helton, 2008). The rank regression is only valid if the relationships are likely monotonic. However, the $R^{2}$ of the rank regression suggests nonmonotonicity (Saltelli et al., 2004). Given the evidence of nonlinearity and nonmonotonicity, we do not think it is appropriate to run MC simulations using the identified elasticities via the parametric approach. Yet, it is important to note that regression-based approaches may be valid in other applications, so we are not opposing parametric and nonparametric approaches, but rather offering an alternative to the case when parametric approaches may not be valid.

\section{Modelling framework and calibration}

In this paper, we proceed to examine empirically the gains of using the MCF approach relative to the use of MC and GQ approaches in an application to European Union's rural development policies using a bi-regional CGE model for the region of Aberdeen City and Aberdeenshire.

\subsection{Model}

The model used for the analysis is taken from Espinosa et al. (2013). While a detailed description of the model is available in the aforementioned paper, we briefly summarize its key features here. The model is a recursive dynamic CGE model that is solves one period at a time. Within each period the basic building block is a static CGE model drawing on the standard IFPRI framework (Lofgren et al., 2002). Following Thurlow (2008), the static model is extended by allowing periodto-period updating of key model parameters, either endogenously or exogenously, and then solving the model recursively by period. In this way, it is possible to generate a dynamic time path for model simulations. Furthermore, a number of modifications have been made so that the model is adapted to reflect the nature of the region under study and to capture the rural and urban areas within this study. In particular, a bi-regional (rural-urban) version of the standard model is developed to capture the intra-regional linkages between the urban and rural part of the region. 
The use of regional CGE models (and particularly dynamic models) has been much less common than their application at the national level. Here, the application of a method developed for the national scale to a single region can be criticized as it potentially misses important interregional feedback effects (Partridge and Rickman, 2010). While a full multiregional CGE model capturing intra-regional rural-urban linkages is theoretically appealing, the extra data demands and the range of assumptions required to implement such an approach makes it difficult to implement. Arguably the remoteness of the study region (which limits interregional commuting) suggests that some of the more important potential interregional feedback effects may be limited in this particular case and therefore that missing these effects may not be too problematic. But the lack of interregional feedback effects in the model should be noted.

In order to run the CGE model, a SAM is required. Appendix A describes the structure and the construction of the SAM for the NUTS 3 region of Aberdeen City and Aberdeenshire.

\subsection{Modelling policy simulations}

The simulated policy scenario is compared with a baseline that represents a situation in which the CAP Health Check and the 2007-2013 rural development programmes are implemented unmodified until 2020. To assess the impact on the rural economy of a CAP Pillar 2 reform, we model the removal of Pillar Axis 3 expenditure (focussed on diversification and quality of life in rural areas). All Pillar 2 Axis 3 funds are redistributed to Axes 1 and 2 (aimed at improving competitiveness of agriculture and forestry and at improving the environment and the countryside respectively) measures in proportion to their shares in the baseline. Simulation results are over the time-span 2006-2020. Such a scenario can be regarded partly reflecting the "refocus" scenario of the impact assessment of Commission's proposals for CAP towards 2020 (European Commission, 2011), where a refocus of CAP on the agricultural sector has been contemplated, in so far it includes deleting axis 3 of Pillar 2. Further information on how the policy simulation was designed for the region under study can be found in Appendix B.

\subsection{Model calibration and closure rules}

Model calibration requires the specification of elasticities, exogenous region-specific trends and closure rules. This parametric calibration reflects the regional economic structure. First, the balance of trade can be satisfied in two ways. The real exchange rate can be endogenised. This allows a change in general purchasing power parity between the region and the rest of the economy. Alternatively, it can be assumed that, because of the small open nature of the regional economy, net savings from the rest of the economy are endogenous. The choice between either closure rules is not straightforward at the regional level and both approaches have been used in the literature (see, e.g., Espinosa et al., 2013; Psaltopoulos et al., 2011). The problem lies in the fact that with a fixed exchange rate, the regional counterpart of a current account deficit has uncertain significance (Waters et al., 1997) as the definition and determination of regional balance of trade deficits is unclear. While there are reasons to assume that external net savings may adjust at the regional level (Dow, 1986), the alternative seems to be more consistent with the actual workings of regional economic adjustment (Rickman, 1992). Therefore, for the current account it is assumed that the real exchange rate is flexible while foreign savings are fixed. Given that all other items are fixed in the external balance (transfers between the rest of the world and domestic institutions), the trade balance is also fixed. For the Savings/Investment balance, investment is considered fixed while savings adjust. For the government balance, as in the case of several CGE models on small regional economies, it was assumed that government savings (the difference between current 
government revenues and current government expenditures) is a flexible residual while all tax rates are fixed. In other words, level of direct and indirect tax rates, as well as real government consumption, are held constant. As such, the balance on the government budget is assumed to adjust to ensure that public expenditures equal receipts.

As for the factor closure rules, for capital we assume that it is sector-specific for the agricultural sector (can move between agricultural farm-sectors), while for the nonfarm economy, it is mobile between sectors and between the rural and urban parts of the region. Land is assumed mobile between agricultural sub-sectors. Finally, for labour, a segmented labour market by skill level and free movement of labour between the rural and the urban areas are assumed. Further, we assume an upward-sloping supply curve for highly-skilled labour, which indicates that highlyskilled labour supply is driven by changes in real wages. For unskilled labour, a neoclassical closure rule was chosen. The choice of closure rules is selected so as to reflect the manner in which the regional economy operates. In this particular case, the choice of government account balance and the external balance was selected mainly due to the size of the region. In the case of labour markets there are very low unemployment rates for skilled labour in the region.

To some extent the closure rule for savings and investment is driven in part by the focus of the paper and the manner in which RDP investment shocks are simulated in the model. In the case of the capital market, the level of sectoral aggregation in the model made the assumption of capital immobility more suitable than the alternatives available.

Table 1 summarises the elasticities that we used in the model. We selected a base elasticity of substitution between factors (bottom level) of 0.8 for all production sectors apart from the six farm types in which we selected an elasticity of 0.2 . We set the top-level factor elasticity to 0.4 for all sectors. We further assumed that elasticities of factor substitution were the same in the rural and urban parts of the study area. We applied Armington elasticities of 2 to all commodities in the model apart from Construction, Distribution, Hotels and catering, Transport, Public Sector and Other Services in which we used an elasticity of 0.5 . 
Similarly, we assumed a CET elasticity of 3 for all sectors but Construction, Distribution, Hotels and catering, Transport, Public Sector and Other Services where we applied a CET elasticity of 0.5 . We set elasticities for market demand for Crops, Livestock, Forestry and Fishing at 0.33 for domestic households and tourists. We set those for all other household, tourist and NPISH elasticities of demand to 1. The household Frisch parameters (which measure the elasticity of the marginal utility of income) were set at the default level of -1 for all household types.

Table 1. Summary of elasticities used in CGE model of Aberdeen City and Shire.

\begin{tabular}{|c|c|}
\hline Elasticity type & Value \\
\hline Production Block & \\
\hline $\begin{array}{l}\text { Top: Substitution between VA and intermediate inputs (for all } \\
\text { sectors) }\end{array}$ & 0.4 \\
\hline $\begin{array}{l}\text { Bottom: Substitution between factors of production (activity- } \\
\text { specific) }\end{array}$ & Range: $0.2-0.8$ \\
\hline Output aggregation & 6 \\
\hline \multicolumn{2}{|l|}{ Trade Block } \\
\hline Armington (commodity-specific) & Range: $0.5-2$ \\
\hline CET (commodity-specific) & Range: $0.5-3$ \\
\hline \multicolumn{2}{|l|}{ Household Consumption } \\
\hline Frisch & -1 \\
\hline Home & $\mathrm{n} / \mathrm{a}$ \\
\hline Market (commodity-specific) & Range: $0.33-1$ \\
\hline
\end{tabular}

\subsection{Monte Carlo Simulation Design}

The procedure for performing MC simulations is to randomly choose a sample value for all elasticities from their specified probability distributions, run the model with this set of parameters and store the model outcomes. This procedure is repeated for a specified number of times. Given a certain number of simulations, the output distributional information approximates the true probability density function of the model output. While there is little evidence regarding the estimation of regional elasticities, the specification of distributions for the MC procedure is not straightforward. In the literature, several studies have assumed uniform distributions. Still, Partridge and Rickman (1998) suggest that because elasticities in CGE models are traditionally econometric estimates, normal (or $t$-) distributions may also be assumed. In addition, the latter type has the advantage of not considering all nearby potentially drawn values as equally probable. 
Therefore, for each of the Armington, transformation and production elasticities, $550^{6}$ values are drawn randomly from a normal distribution, with a standard deviation of 50 per cent, and independently from one another. As a result of the lack of econometric estimation, it is difficult to judge the uncertainty surrounding the use of regional elasticities. For this reason, the standard deviations are large with respect to the benchmark elasticity value to account for this issue. The means of the distribution are either the best corresponding estimate within the range of estimates found in the literature (e.g. Ha et al., 2010) or alternatively the "best guess" taking into account commonly expressed intuitions in the literature (Partridge and Rickman, 1998; Holland, 2010).

\section{Identification of key elasticities}

This section details the practical implementation of the MCF approach and presents the results of the identification step. In the literature, parametric methods (e.g., regression-based approach), which assume a priori an underlying structure of the relationship under study, have been used to reveal the link between elasticities and model outputs in a CGE model (see Belgodère and Vellutini, 2011). However, as discussed in the introduction, parametric methods do not consistently capture the structure of the model and hence the strength of the results obtained may be difficult to judge.

In this application, the MCF is applied on the following groups of elasticities: Armington elasticities, transformation elasticities, elasticities of substitution between production factors and elasticities of substitution between production factors and intermediate inputs; overall, the total number of elasticities tested is 136. The output of interest is agricultural GDP. The choice of the base criterion translates our interest in the main objective of Pillar 2, which is to support growth and diversification of rural areas. It is indeed likely that policymakers evaluate the implementation of a new rural development policy (or changing an existing policy) by weighing the budgetary costs to its benefits where the latter can arguably be measured by the additional agricultural growth induced.

As explained above, the first step for the MCF approach is to obtain results from a MC analysis; once we obtain the results from a simple MC approach, we partition the vector of model outputs produced by the $J$ simulations into two groups, using the following criteria, whether agricultural GDP is below or above the mean of agricultural GDP calculated across all MC simulation results. Both the 'low GDP' and 'high GDP' groups are associated with their corresponding vectors of elasticities. Two-sample Kolmogorov-Smirnov tests are then performed independently for each factor to assess whether a specific parameter is either important or not.

It is important to note this step is sensitive to whether the mean obtained via the MC has converged. In many applications, researchers may not know whether the mean has stabilized because of the infeasibility or unpracticality of running their models for a high number of solves. Also, the mean may have stabilized for some variables of interest but not for others, especially in regional models with high levels of disaggregation (as we discuss above). So there is indeed a possibility that the grouping might be wrong and warn this could be a source of bias. This is a clear caveat of the analysis. Despite this problem, the MCF performs well in our application. One easy solution may be to increase the number of original MC simulations. But it also affects the relative advantage of the approach vis-à-vis the traditional MC approach, by requiring additional model

\footnotetext{
${ }^{6}$ While this is an arbitrary number of simulations, we choose 550 simulations because it is roughly the double of the number needed to run the Stroud simulations (i.e., $272 \times 2=544$ ), as further explained in Section 5.2.
} 
solves. In our application, we can 'cheat' this problem and use the mean obtained from the GQ simulations (less than 0.05 deviation from the MC mean) and confirm that this does not affect the results. Yet it is important to mention that groupings based on different indicators would be likely to be subject to higher deviations and biases.

With this caveat in mind, Table C1 (Appendix C) summarises the results from MCF and show that out of all 136 elasticities, 66 influence the model outcome (i.e. agricultural GDP). Among those, 17 are deemed to be critical (or highly important) in the relationship between inputs and output and are distributed across the different groups of elasticities (Table 2). We focus the discussion on these highly important elasticities, which illustrate the usefulness of the MCF method in providing information which helps validate the model, and illustrating the key linkages in the model.

The results in Table 2 are driven by two essential elements, i.e., the structure of the economy and the nature of the policy shock. In view of the nature of the shock (i.e., a shift from a diversification of rural development policy to a much more agriculture-centred policy), we find, as we would expect, that trade elasticities which are directly linked to agricultural commodities and commodities directly affected by the policy change (i.e., Crops, Livestock, Forestry, Public services for Armington/Transformation elasticities), are among the most important in the model. Similarly, production and substitution elasticities that are related to Large Cereal/Other farms in the rural area are deemed critical.

Also, the structure of the regional economy plays a key role in determining results in Table 2. For example, the fact that Armington elasticities for food processing and other food industries are highly important reflects the large importance of the regional economy in Scotland's food and drink processing sector (about 30\%). To a lesser extent, the Armington elasticity for oil and the production/substitution elasticities for the urban activity of mining are among the most important ones, possibly due to the sizeable oil extraction and drilling activities in the region (but focussed in the urban centre). Armington elasticities for oil and financial services are also logically critical or important (due to their weight in intermediate consumption of agriculture) as well as transformation elasticities for the main commodities used in the processing of agricultural goods, e.g., machinery, drink, transport.

Considering both critical and important production and trade elasticities, the predominant activities and commodities involved are both agricultural (e.g., Crops), reflecting the nature of the scenario implemented, and from other sectors (e.g., food processing, mining, oil), reflecting the structure of the regional economy. 
Table 2. Most important elasticities in CGE model.

Armington (6)

Crops, Livestock, Financial services, Public services, Food processing, Other food industries

Transformation (4)

Crops, Machinery, Hotels, Transports

Substitution between production factors and intermediate inputs (4)

U-Mining, R-Hotels, R-Large Cereal Farms, R-Large Other Farms

\section{Substitution between production factors (3)}

U-Mining, R-Large Cereal Farms, R-Large Other Farms

Notes: $\mathrm{U}$ and $\mathrm{R}$ stand respectively for Urban and Rural

More importantly, this result shows that the impact patterns of a relatively marginal and redistributive shock in the rural area of Aberdeen will be significantly determined by the structure of sectors which are predominantly located in the urban area of the region (e.g. financial services, food processing). In other words, Table 2 implicitly suggests the existence of strong linkages between rural and urban areas.

\section{Comparing SSA outputs}

\subsection{Base results discussion}

As explained earlier, we model a redistribution of Axis 3 funds towards Axes 1 and 2, i.e. funds will be taken away from measures which aim at improving the quality of life in rural areas and encouraging diversification of economic activity, to be proportionally reallocated towards improving the competitiveness of agriculture and forestry and improving the environment and the countryside. This policy scenario is expected to lead to several impacts. First, the removal of Axis 3 will negatively impact on non-agricultural rural GDP with capital stocks reduced in affected sectors, e.g. tourism and energy.

This scenario may decrease output levels in these sectors, leading to a GDP decrease in the secondary (e.g., energy) and tertiary sectors (e.g., tourism). To a lesser extent, the Other Primary (Forestry) sector may also be affected. Depending on the linkages to labour markets, this may put downward pressure on wages, particularly for unskilled workers if the impact on the tourist industries is significant. This type of effect may spillover into the urban part of the region. On the other hand, increased funds in Axes 1 and 2 will increase agricultural output via both the coupled nature of the payments and increases in agricultural capital stock. This may lead to a decline in regional agricultural prices leading to positive impacts on downstream industries and agricultural exports as well as for farmers' income. 
Table 3 presents the simulation results based on the standard MC analysis (second column). The effects of the shock are measured as deviations from model-specific baseline values. Given the redistributive and limited nature of the policy shock, the overall impact of the transfer of the Axis 3 funds to Axes 1 and 2 would have very small effects on regional GDP both in the urban area $(+0.25 \%)$ and in the rural area $(-0.19 \%)$, leading in turn to a marginally positive aggregate effect on the economy of Aberdeen (+0.10\%). As expected, we can see that the concentration of Pillar 2 funds solely on Axis 1 and 2 measures and the associated higher investment benefits for local farming and higher coupled support would indeed boost agricultural GDP $(+2.63 \%)$.

The policy scenario would also have some unexpected effects. For example, GDP for the rural tertiary sector, e.g. hotels, would also increase by $0.33 \%$. This result appears rather counterintuitive with respect to the nature of the policy scenario, which implies decreased investments in this sector and will be further discussed below. Regarding employment effects, we find similar patterns of impacts as those described above for GDP. For instance, associated to the increase in rural agricultural activity, agricultural employment would strongly increase in the rural area $(+2.89 \%)$.

The contrary impacts on rural and urban employment (respectively $+0.24 \%$ and $-0.44 \%$ ) result logically from the impacts on the economy activity in both areas, and would offset each other to lead to the absence of any impact on total employment. For most sectors, the pattern of employment impacts remains directly connected to the impacts on GDP, except for the rural tertiary sector. Surprisingly, rural employment in the tertiary sector would decrease by 0.61 per cent, while the GDP of the sector would increase by 0.33 per cent.

Finally, despite the fact there would be an increase in agricultural output, the impact on revenue for agricultural households would be partly mitigated $(-0.72 /-3.21 \%)$ due to the combination of reduced agricultural prices and reduced factor income flows from non-agricultural activities associated with Axis 3 investment.

\subsection{Comparison of SSA approaches}

We now proceed to the comparison of SSA approaches using Table 3. Column 3 presents the results obtained via the MCF approach (i.e., we re-run the Monte Carlo procedure, but this time, only with the elasticities identified as highly important or critical as reported in Appendix C (Table $\mathrm{C1}$ ). As a reference point to compare the different approaches, we also compute the results obtained via a Gaussian Quadrature (Stroud, 1957). The GQ has quickly become the most common approach for SSA because the GQ requires a limited amount of simulations and is easy to design and implement (Artavia et al., 2015; Villoria and Preckel, 2017; Chatzivasileiadis, 2018). As noted in the introduction, this gain in terms of computing time comes at certain costs; namely, if more general distributions are considered, e.g., nonsymmetric distributions, these methods are significantly more difficult to apply in practical modelling (DeVuyst and Preckel, 2007) and the restricted sampling in GQ may not be desirable in some applications (e.g., modelling of thresholds, tariffs, or quotas). In this context, we use normal distributions and there are no features of the policy implemented that create kinks, corners or bounds that would be problematic for GQ. Indeed, GQ perform best in these environments and therefore are our reference point to evaluate the MCF and $\mathrm{MC}$ approaches. 
Table 3. Average impacts of policy shock in Aberdeen City and Shire, 2006-2020, \% change.

\begin{tabular}{|c|c|c|c|}
\hline$G D P$ & $\begin{array}{c}\text { Monte Carlo } \\
\text { (1) }\end{array}$ & $\begin{array}{l}\mathrm{MCF} \\
(2)\end{array}$ & $\begin{array}{c}\text { Stroud } \\
(3)\end{array}$ \\
\hline Total & $\begin{array}{l}0.10 \% \\
(1.556)\end{array}$ & $\begin{array}{c}0.01 \% \\
(1.410)\end{array}$ & $\begin{array}{l}-0.04 \% \\
(0.009)\end{array}$ \\
\hline Urban & $\begin{array}{l}0.25 \% \\
(2.535)\end{array}$ & $\begin{array}{c}0.18 \% \\
(4.677)\end{array}$ & $\begin{array}{l}0.16 \% \\
(0.138)\end{array}$ \\
\hline Rural & $\begin{array}{l}-0.19 \% \\
(4.232)\end{array}$ & $\begin{array}{l}-0.31 \% \\
(1.899)\end{array}$ & $\begin{array}{l}-0.41 \% \\
(0.035)\end{array}$ \\
\hline Agriculture & $\begin{array}{l}2.63 \% \\
(2.855)\end{array}$ & $\begin{array}{l}2.57 \% \\
(1.919)\end{array}$ & $\begin{array}{l}2.47 \% \\
(0.025)\end{array}$ \\
\hline Other Primary & $\begin{array}{c}0.18 \% \\
(12.761)\end{array}$ & $\begin{array}{l}-0.03 \% \\
(1.472)\end{array}$ & $\begin{array}{l}-0.16 \% \\
(0.032)\end{array}$ \\
\hline Rural Secondary & $\begin{array}{l}-0.06 \% \\
(2.217)\end{array}$ & $\begin{array}{l}-0.09 \% \\
(1.670)\end{array}$ & $\begin{array}{l}-0.22 \% \\
(0.016)\end{array}$ \\
\hline Rural tertiary & $\begin{array}{l}0.33 \% \\
(2.711)\end{array}$ & $\begin{array}{l}-0.53 \% \\
(1.833)\end{array}$ & $\begin{array}{l}-0.62 \% \\
(0.023)\end{array}$ \\
\hline Urban secondary & $\begin{array}{l}0.12 \% \\
(1.684)\end{array}$ & $\begin{array}{l}0.16 \% \\
(1.605)\end{array}$ & $\begin{array}{l}0.04 \% \\
(0.018)\end{array}$ \\
\hline Urban tertiary & $\begin{array}{c}0.27 \% \\
(1.505)\end{array}$ & $\begin{array}{c}0.20 \% \\
(1.445)\end{array}$ & $\begin{array}{l}0.21 \% \\
(0.019)\end{array}$ \\
\hline \multicolumn{4}{|l|}{ Employment } \\
\hline Total & $\begin{array}{l}-0.01 \% \\
(0.168)\end{array}$ & $\begin{array}{c}0.00 \% \\
(0.121)\end{array}$ & $\begin{array}{l}0.00 \% \\
(0.001)\end{array}$ \\
\hline Urban & $\begin{array}{c}0.24 \% \\
(11.682)\end{array}$ & $\begin{array}{c}0.22 \% \\
(8.008)\end{array}$ & $\begin{array}{l}0.24 \% \\
(0.185)\end{array}$ \\
\hline Rural & $\begin{array}{l}-0.44 \% \\
(4.838)\end{array}$ & $\begin{array}{l}-0.43 \% \\
(1.815)\end{array}$ & $\begin{array}{l}-0.49 \% \\
(0.041)\end{array}$ \\
\hline Agriculture & $\begin{array}{l}2.89 \% \\
(2.944)\end{array}$ & $\begin{array}{l}2.98 \% \\
(1.536)\end{array}$ & $\begin{array}{l}3.26 \% \\
(0.038)\end{array}$ \\
\hline Other Primary & $\begin{array}{l}0.16 \% \\
(2.880)\end{array}$ & $\begin{array}{l}-0.07 \% \\
(1.007)\end{array}$ & $\begin{array}{l}-0.14 \% \\
(0.104)\end{array}$ \\
\hline Rural Secondary & $\begin{array}{l}-0.08 \% \\
(2.232)\end{array}$ & $\begin{array}{c}0.09 \% \\
(1.104)\end{array}$ & $\begin{array}{l}-0.01 \% \\
(0.069)\end{array}$ \\
\hline Rural tertiary & $\begin{array}{l}-0.61 \% \\
(2.295)\end{array}$ & $\begin{array}{l}-0.59 \% \\
(1.687)\end{array}$ & $\begin{array}{l}-0.67 \% \\
(0.037)\end{array}$ \\
\hline Urban secondary & $\begin{array}{l}0.05 \% \\
(1.850)\end{array}$ & $\begin{array}{c}0.01 \% \\
(0.823)\end{array}$ & $\begin{array}{l}0.00 \% \\
(0.039)\end{array}$ \\
\hline Urban tertiary & $\begin{array}{c}0.28 \% \\
(1.121)\end{array}$ & $\begin{array}{c}0.29 \% \\
(0.474)\end{array}$ & $\begin{array}{l}0.32 \% \\
(0.036)\end{array}$ \\
\hline Income & & & \\
\hline Rural households & $\begin{array}{l}0.00 \% \\
(1.934)\end{array}$ & $\begin{array}{c}0.07 \% \\
(1.265)\end{array}$ & $\begin{array}{l}0.03 \% \\
(0.004)\end{array}$ \\
\hline Small farm households & $\begin{array}{l}-0.72 \% \\
(1.250)\end{array}$ & $\begin{array}{l}-0.90 \% \\
(1.739)\end{array}$ & $\begin{array}{l}-0.93 \% \\
(0.147)\end{array}$ \\
\hline Large farm households & $\begin{array}{l}-3.21 \% \\
(2.303)\end{array}$ & $\begin{array}{l}-3.77 \% \\
(2.691)\end{array}$ & $\begin{array}{l}-3.89 \% \\
(0.343)\end{array}$ \\
\hline
\end{tabular}

Notes: standard deviations in brackets. 
Stroud analysis approximates the moments of the joint distribution of the parameters using a discrete joint probability distribution evaluated over a finite number of points. The variance for each parameter is consistent with the assumption that observed parameter values are drawn from independent uniform distributions with lower and upper bound equal to $+/-50$ per cent of the mean estimate. For a model with $T$ jointly distributed parameters, there are $2 T$ Stroud points at which the model must be evaluated (i.e., 272 times). ${ }^{7}$ For the analysis, we use an Intel Xeon X5680 running under the 32-bit version of Windows XP Professional 2002 (with $6 \mathrm{CPU}$ at $3333 \mathrm{MHz}$ and 3 GB RAM).Computation times for the MC analysis, the MCF and the Stroud analysis are respectively 36 hours 43 minutes, 25 hours 42 minutes, and 11 hours 29 minutes.

There are a few things to consider when analysing the results in Table 3. First, as explained above, some of the Monte Carlo analysis results were somewhat counter-intuitive. In particular, the MC estimate of the expected impact on Rural GDP in the tertiary sector suggested that the impact of the reduction of investment in this sector would increase GDP. However, we see that the impact patterns significantly change for the MCF and Stroud results. Specifically, while the rural tertiary GDP estimate increases by 0.33 per cent according the MC analysis it decreases when the MCF or Stroud analysis are used (respectively, $-0.53 \%$ and $-0.62 \%$ ). This suggests the approximation error in the MC results in this case are large (this is likely because the MC results have yet to converge), while the results obtained with MCF and Stroud analyses are consistent with the expected a priori impacts of the policy shock. A similar result can be found for GDP and employment in the Other Primary sector. The signs of other GDP, employment and income impact patterns remain in line with those obtained using MCF or Stroud analysis.

We have assessed the results from a structural perspective, with respect to potential sign changes in the impact patterns, and now turn to a more quantitative approach in order to evaluate the overall relative quality of $\mathrm{MC}$ and $\mathrm{MCF}$ analyses. Using results from the GQ as a reference point, a quick look at Table 3 does not confirm whether MCF outperforms MC. To clarify this conjecture, we calculate the standard percentage error (STPE) and a simple absolute difference (AD) to evaluate the proximity of results obtained via MC and MCF analyses to those obtained using a GQ. Calculations are made on average for each sub-group of results in Table 3 (i.e., GDP, employment, income). For the AD, smaller numbers indicate close proximity between MC-based results and GQ results. For the STPE, values close to 1 indicate very close proximity, while values above (or below) 1 display an over(under)-estimation of the impact patterns obtained via Stroud analysis.

Table 4 presents the calculated proximity measures. Across all results, we find that the MCF has much smaller AD than those given by MC analysis. Similarly, STPE values confirm that MCF outperforms MC analysis. Last, we can examine the precision of results of each approach when looking at standard deviations in Table 3. Overall, the main finding in Table 3 is that relative to the MC case the MCF gives more precise results in most cases, especially for employment and GDP effects. Consequently, policy implications that are drawn from the MCF are relatively more reliable.

To check whether these results are sensitive to the closure rules, we redo the analysis assuming flexible foreign savings and find that the choice for this closure rule does not change our results. Interestingly, Table $\mathrm{C} 2$ in Appendix $\mathrm{C}$ shows that the number of critical elasticities is much larger (52 against 17) with this alternative closure rule. Despite this, Table 5 shows that the MCF

\footnotetext{
${ }^{7} 550$ simulations are run for the MC and MCF approaches.
} 
still outperforms the $\mathrm{MC}$ approach, as the former gives $\mathrm{AD}$ values that are lower than for the $\mathrm{MC}$ approach while the STPE values of the MCF results are much closer to those implied by the GQ than the results from the MC approach. We do not examine how simulation results respond to changes in other closure rules because they are set to fundamentally represent the regional nature of the model as well as the design of the policy simulations.

Table 4. Proximity measures to Stroud results.

\begin{tabular}{llll}
\hline & & $\begin{array}{l}\text { MC } \\
(1)\end{array}$ & $\begin{array}{l}\text { MCF } \\
(2)\end{array}$ \\
\hline \multirow{2}{*}{ GDP } & STPE & 0.393 & 1.007 \\
& AD & 0.246 & 0.083 \\
Employment & STPE & 5.787 & 0.573 \\
& AD & 0.106 & 0.074 \\
Income & STPE & 0.553 & 1.384 \\
& AD & 0.305 & 0.062 \\
\hline
\end{tabular}

Table 5. Proximity measures to Stroud results (alternative closure rule).

\begin{tabular}{llcc}
\hline \multirow{2}{*}{ GDP } & & MC & MCF \\
& & $(1)$ & $(2)$ \\
\multirow{2}{*}{ Employment } & STPE & 1.557 & 1.099 \\
& AD & 0.219 & 0.038 \\
Income & STPE & 1.778 & 0.981 \\
& AD & 0.507 & 0.271 \\
& STPE & 0.172 & 0.314 \\
\hline
\end{tabular}

\section{Concluding remarks}

This paper develops and applies Monte Carlo Filtering as an alternative approach to Systematic Sensitivity Analysis for Computable General Equilibrium modeling. This both identifies the most influential parameters in the model in terms of their influence on model outcomes and provides robust policy impact estimates. The approach has the flexibility of the Monte Carlo approach in that it can easily deal with nonsymmetric and general non-independent distributions. By limiting the dimensionality considered, it reduces the Monte Carlo approximation error. The paper illustrates the proposed Monte Carlo filtering approach, and shows how its results compare to the alternative standard Monte Carlo and Gaussian quadrature approaches to systematic sensitivity analysis (SSA), in relation to an analysis of the impact of EU rural development policies using a regional CGE model of Aberdeen City and Aberdeenshire. We find that Monte Carlo analysis provides counter-intuitive results, possibly due to the approximation error, and more fundamentally that the Monte Carlo Filtering approach outperforms Monte Carlo analysis, making it a viable option for SSA.

Furthermore, by identifying the important and critical parameters within the modeling, it provides an additional method to both validate the computable general equilibrium model and 
understand the key linkages of the model and the economy to which the model has been applied. In this case, we find that that the impact patterns of the policy change are significantly determined, on one hand, by elasticities that are directly affected by the shock and, on the other hand, by elasticities that reflect the structure of the regional economy. Given the geographical location of activities, this result suggests the existence of substantial linkages between rural and urban areas in the region.

More generally, developing the approach and in particular how it can be applied in a structured way to examine linkages within the economy would appear to be a fruitful area for future research. Further comparisons of the three SSA approaches across other models and situations, e.g., where nonstandard distributions may be important, would provide further useful evidence of the relative potential of the Monte Carlo Filtering approach.

\section{Acknowledgements}

The views expressed are purely those of the authors and may not in any circumstances be regarded as stating an official position of the European Commission or the University of Aberdeen. The authors would like to thank Maria Espinosa, Sergio Gomez y Paloma, three reviewers and the editor for valuable comments, and Javier Alba (and the IPTS-IT department) for technical assistance.

Disclosure statement. No potential conflict of interest was reported by the authors.

\section{References}

Anthoff, D. and R.S.L. Tol (2013) The uncertainty about the social cost of carbon: A decomposition analysis using fund. Climatic Change, 117, 515-530.

Arndt, C. (1996) An introduction to systematic sensitivity analysis via Gaussian quadrature. GTAP Technical Paper, No. 2, July, Purdue University.

Arndt, C. and T. W. Hertel (1997) Revisiting "The fallacy of free trade". Review of International Economics, 5, 221229.

Artavia, M., H. Grethe, and G. Zimmermann (2015) Stochastic market modelling with Gaussian quadratures: do rotations of Stroud's octahedron matter?. Economic Modelling, 45, 155-168.

Bascou, P., P. Londero, and W. Munch (2006) Policy reform and adjustment in the European Union: changes in the CAP and enlargement. In D. Blandford and B. Hill (eds), Policy Reform and Adjustment in the Agricultural Sectors of Developed Countries. Wallingford: CABI, pp. 55-68.

Belgodère A. and C. Vellutini (2011) Identifying key elasticities in a CGE model: a Monte Carlo approach. Applied Economics Letters, 1-4.

Chatzivasileiadis, T. (2018) Quasi-Monte Carlo application in CGE systematic sensitivity analysis. Applied Economics Letters, 25, 1521-1526.

Chatzivasileiadis, T., F. Estrada, M.W. Hofkes, and R.S.J. Tol (2017) Systematic sensitivity analysis of the full impacts of sea level rise. Computational Economics, ISSN 0927-7099.

De Vuyst, E.A. and P.V. Preckel (1997) Sensitivity analysis revisited: A quadrature-based approach. Journal of Policy Modeling, 19, 175-185.

De Vuyst, E.A. and P.V. Preckel (2007) Gaussian cubature: A practitioner's guide. Mathematical and Computer Modeling, 45, 787-794.

Dow, S.C. (1986) The capital account and regional balance of payments problems. Urban Studies, 23, 173-184.

Espinosa M., D. Psaltopoulos, F. Santini, E. Phimister, D. Roberts, S. Mary, T. Ratinger, D. Skuras, E. Balamou, M.A. Cardenete, and S. Gomez y Paloma (2013) Ex-ante analysis of the regional impacts of the common agricultural policy: a rural-urban recursive dynamic CGE model approach. European Planning Studies, DOI:10.1080/09654313.2013.786683. 
European Commission (2011) Proposal for a Regulation of the E. Parliament and of the Council on support for rural development by the European Agricultural Fund for Rural Development (EAFRD).\{SEC(2011) $1153\}\{$ SEC(2011) 1154\}. Brussels, 19.10.2011. COM(2011) 627 final/2.

Gilchrist, D. A. and L. V. St. Louis (1994) An equilibrium analysis of regional industrial diversification. Regional Science and Urban Economics, 24, 115-133.

Gillespie, G., P. G. McGregor, J. K. Swales, and Y. P. Yin (2001) The displacement and multiplier effects of regional selective assistance: a computable general equilibrium analysis. Regional Studies, 35, 125-139.

Ginsburgh, V. and M. Keyzer (1997) The Structure of Applied General Equilibrium Models. MIT Press.

Gohin, A. and L. Latruffe (2006) The Luxembourg Common Agricultural Policy Reform and the European food industries: what's at stake?. Canadian Journal of Agricultural Economics, 54, 175-94.

Ha, S.J., K. Turner, G. Hewings, P. McGregor, and K.J. Swales (2010). Econometric estimation of Armington import elasticities and their system-wide impact in a regional CGE model of the Illinois economy, Stirling Economics Discussion Paper 2010-19, December.

Haber, S. (1970) Numerical integration of multiple integrals. SIAM Review, 12, 481-526.

Hermeling, C. and T. Mennel (2008) Sensitivity analysis in economic simulations: a systematic approach. $Z E W$ Discussion Papers 08-068, Center for European Economic Research, Mannheim, Germany. Available online in October 2018 at https://ub-madoc.bib.uni-mannheim.de/2100/1/dp08068.pdf.

Holland, D. (2010) What happens when exports expand: some ideas for closure of regional computable general equilibrium models. Annals of Regional Science, 45, 439-451.

Hyytiä, N. (2011) Allocation of CAP modulation funds to rural development measures at the regional level in Finland, Paper prepared for presentation at the EAAE 2011 Congress Change and Uncertainty, August 30 to September 2, 2011, Zurich, Switzerland.

Keyzer, M. A., M. D. Merbis, and M. van Riet (2002) The CAP Reform Proposal of the Mid-term Review: Decoupling with Strings Attached. Amsterdam: Centre for Word Food Studies.

Kilkenny, M. (2008) The new rural economics. Chapter 5 in Wu, J., Barklay, P. W. and Weber, B. A. (eds.), Frontiers in Resource and Rural Economics: Human-Nature, Rural-Urban Interdependencies. Washington D.C.: RFF Press Book, pp. 63-81.

Lima M. C. and M. A. Cardenete (2007) The effects of European Structural Funds in a regional economy: an applied general equilibrium analysis. Applied Economic Letters, 14, 851-855

Lofgren, H., R. L. Harris, and S. Robinson (2002) A standard computable general equilibrium model (CGE) in GAMS. Microcomputers in Policy Research, 5. Washington: IFPRI, pp. 42-45.

Mattas, K. A. and C. M. Shrestha (1991) A new approach to determining sectoral priorities in an economy: inputoutput elasticities. Applied Economics, 23, 247-254.

Miller, R E. and P.D. Blair (2009) Input-Output Analysis: Foundations and Extensions, $2^{\text {nd }}$ ed. New York: Cambridge University Press.

Neuhauser, M., A. Welz and G.D. Ruxton (2017) Statistical tests for the comparison of two samples: the general alternative. Communications in Statistics - Simulation and Computation 46, 903-909.

Partridge, M. D. and D. S. Rickman (1998) Regional computable general equilibrium modeling: a survey and critical appraisal. International Regional Science Review, 21, 205-248.

Partridge, M. D. and D. S. Rickman (2010) Computable general equilibrium (CGE) modelling for regional economic development analysis. Regional Studies, 44, 1311-1328.

Phimister, E. and D. Roberts (2012) The role of ownership in determining the rural economic benefits of on-shore wind farms. Journal of Agricultural Economics, 63, 331-360. 
Preckel P.V., M. Verma, T.W. Hertel and W. Martin (2011) Systematic sensitivity analysis for GTAP - where Wwe've been and where we're going. Selected Paper for $14^{\text {th }}$ Annual Conference on Global Economic Analysis, 1618 June 2011, Venice, Italy.

Psaltopoulos D., E. Balamou, D. Skuras, T. Ratinger, S. Sieber (2011) Modelling the impacts of CAP Pillar 1 and 2 measures on local economies in Europe: testing a case study-based CGE model approach. Journal of Policy Modelling, 33, 53-69.

Rickman, D. (1992) Estimating the impacts of regional business assistance programs: alternative closures in a computable general equilibrium model. Papers in Regional Science, 71, 421-35.

Roberts, D. (1995) UK agriculture in the wider economy: the importance of net SAM linkage effects. European Review of Agricultural Economics, 22, 495-511.

Robinson, S., A. Cattaneo and M. El-Said (2001) Updating and estimating a social accounting matrix using cross entropy methods. Economic Systems Research, 13, 47-64.

Saltelli A., M. Ratto, T. Andres, F. Campolongo, J. Cariboni, D. Gatelli, M. Saisana and S. Tarantola, eds. (2008) Global Sensitivity Analysis. The Primer. John Wiley and Sons, Ltd.

Saltelli A., S. Tarantola, F. Campolongo and M. Ratto (2004) Sensitivity Analysis in Practice - A Guide to Assessing Scientific Models. John Wiley and Sons Ltd.

Storlie C. B., and J. C. Helton (2008) Multiple predictor smoothing methods for sensitivity analysis: Description of techniques. Reliability Engineering and System Safety 93, 28-54.

Stroud, A. H. (1957) Remarks on the disposition of points in numerical integration formulas. Mathematical Tables and Other Aids to Computation, 11, 257-261.

Thurlow, J. (2008) A Recursive Dynamic CGE Model and Microsimulation Poverty Module for South Africa. Washington: IFPRI. Available online www.tips.org.za/files/2008/Thurlow_J_SA_CGE_and_microsimulation_model_Jan08.pdf

Törmä, H. and H. Lehtonen (2009) Macroeconomic and welfare effects of the CAP reform and further decoupling of agricultural support in Finland: A CGE modelling approach. Food Economics - Acta Agriculturae Scandinavica, Section C, 6, 73-87.

Villoria, N.B. and P.V. Preckel (2017) Gaussian quadratures vs. Monte Carlo experiments for systematic sensitivity analysis of computable general equilibrium model results. Economics Bulletin, 37, 480-487.

Waters, E.C., D.W. Holland and B. Weber (1997) Economic impacts of a property tax limitation: a computable general equilibrium analysis of Oregon's Measure 5. Land Economics, 73, 72-89.

Wiggle, R.M. (1991) The Pagan-Shannon approximation: unconditional systematic analyses in minutes. Empirical Economics, 16, 35-49. 


\section{Appendix A. Creation of the SAM}

Stage 1 involved the regionalisation of existing national supply and use tables for year 2005 (Scottish Government, 2013). To avoid disclosure issues, a full supply matrix is not published for the whole of Scotland. But an aggregate $11 \times 11$ supply matrix is released along with detailed percentage market share and percentage secondary production information for 126 sectors/commodities. The latter has been used to create a national supply matrix at the required level of sector and commodity disaggregation (see Appendix Table A1) while the national 126 $\times 126$ use matrix was collapsed to this same level of aggregation.

Using these two (national) tables, in conjunction with data on employment from the Annual Business Inquiry workplace analysis (NOMIS, 2009), we produced a balanced regional set of accounts for the Aberdeen City and Aberdeenshire region for calendar year 2005 maintaining a commodity-by-industry distinction throughout the process. We applied simple employment location quotients (Flegg and Tohmo, 2013) to generate import flows; initial export levels were calculated residually.

This was followed by the rural-urban disaggregation of sectors, households and factors of production through the use of secondary data. The latter again included employment data from the Annual Business Inquiry workplace analysis but this time at subregional level (NOMIS, 2009), as well as information from the 2001 population Census (General Register Office for Scotland, 2013) and the Annual Survey of Hours and Earnings (ONS, 2006) to split the household accounts. The definitions of rural and urban sub-areas were, for convenience, based on administrative boundaries. In particular, firms and households within the Aberdeen City Local Authority area were classified as urban, while firms and households within the Aberdeenshire Local Authority were classified as rural.

Stage 3 involved the disaggregation of agricultural activity through the use of FADN (Farm Accountancy Data Network) information on the farm-typology (see Mary et al., 2013). The regional accounts were then converted into a (square) social accounting matrix (SAM) structure and by filling in the inter-institutional transactions. The latter draws on regional household income and expenditure data (Office for National Statistics, 2007), as well as information from regional agencies (Scottish Enterprise, 2009). Up to this point in the construction process, all of the information used was from publically available secondary sources. In Stage 4, some of the SAM entries relating to key sector in the region were "superiorised", in other words replaced with values considered more accurate, collected from interviews with local policymakers and stakeholders. This information was considered to be more accurate than the values generated through mechanical regionalisation processes. As a result, some of the row and column totals of the SAM became unbalanced and the final stage of the construction process (Stage 5) involved the application of the cross-entropy optimisation procedure (Robinson et al., 2001) in order to estimate a balanced SAM.

The activity accounts included in the SAM are shown in Appendix Table A1. Each production sector is represented in the rural and urban part of the SAM (even though their significance in each area may be very different), resulting in 48 sectors in total. Twelve different farm accounts are distinguished in the SAM according to farm type and farm size. Only the two major farm types in the region (specialist cereals and specialist livestock) are shown separately, with the remaining FADN farm types aggregated into an "Other" category. In terms of downstream food processing sectors, despite original intentions, meat processing was aggregated with "other foods" due to the need to preserve confidentiality while the fish processing and fruit and vegetable 
processing are combined reflecting the level of aggregation in the national 126 sector input-output tables. The 20 commodity accounts in the Aberdeen and Aberdeenshire SAM reflect closely the production sectors. The main difference relates to agricultural output where two commodity types are distinguished - crops and livestock. Four factors of production are distinguished in the Aberdeen and Aberdeenshire SAM - two types of labour (skilled and unskilled), capital and land, the latter defined such that it only includes agricultural and forestry land. The capital account in the matrix includes, in addition to returns to capital, gross profit and payments for self-employment (the latter form of labour dominates agricultural labour input in the region). Four different household groups are distinguished in the Aberdeen and Aberdeenshire SAM:

- Urban households - Households resident in Aberdeen City local authority area

- Rural households - Households resident in Aberdeenshire local authority area

- Small farm households - Households managing farms of less than 40 European Size Units (ESU)

- Large farm households - Households managing farms of 40 or more ESUs

The small farm household category receives factor income from the small farm types, the large from the large farm types. An explicit tourist household account is also included. For accounting purposes, an account reflecting non-profit institutions serving households is included to capture the expenditure of such institutions. Finally a combined (local and central) government account, single ROW account and investment-savings account are distinguished in the matrix. 
Table A1: Classification of Production sectors and commodity accounts in the_Aberdeen and Aberdeenshire SAM

\begin{tabular}{|c|c|c|c|c|c|}
\hline $\begin{array}{l}\text { SAM } \\
\text { Code }\end{array}$ & Name/Production Sectors & NACE & $\begin{array}{l}\text { SAM } \\
\text { Code }\end{array}$ & Name/Commodity Accounts & SIC 2003 \\
\hline 1 & Small cereal farms & 01 (part) & 1 & Crops & 01 (part) \\
\hline 2 & Large cereal farms & 01 (part) & 2 & Livestock & 01 (part) \\
\hline 3 & Small livestock farms & 01 (part) & 3 & Forestry & 02 \\
\hline 4 & Large livestock farms & 01 (part) & 4 & $\begin{array}{l}\text { Fishing and service activities } \\
\text { incidental to fishing (incl. fish } \\
\text { farming) }\end{array}$ & 05 \\
\hline 5 & Small other farm types & 01 (part) & 5 & $\begin{array}{l}\text { Extraction of crude petroleum and } \\
\text { natural gas plus associated services; } \\
\text { mining }\end{array}$ & 11,12 \\
\hline 6 & Large other farm types & 01 (part) & 6 & Other Mining & 10,14 \\
\hline 7 & Forestry & 02 & 7 & $\begin{array}{l}\text { Processing and preserving of fish } \\
\text { and fish products; fruit and } \\
\text { vegetables }\end{array}$ & $15.2,15.3$ \\
\hline 8 & Fishing and service activities incidental to fishing (incl. fish farming) & 05 & 8 & Other food products & $\begin{array}{l}15.1,15.4- \\
15.8\end{array}$ \\
\hline 9 & Extraction of crude petroleum and natural gas plus associated services; mining & 11,12 & 9 & Alcoholic and soft drinks & 15.90 \\
\hline 10 & Other Mining & 10,14 & 10 & $\begin{array}{l}\text { Wood and paper products (except } \\
\text { furniture) }\end{array}$ & $\begin{array}{ll}20, & 21.1 \\
21.2 & \end{array}$ \\
\hline 11 & Processing and preserving of fish and fish products; fruit and vegetables & $15.2,15.3$ & 11 & Machinery & 29 \\
\hline 12 & Other food products & $15.1,15.4-15.8$ & 12 & Other manufacturing & $\begin{array}{l}\begin{array}{l}16-19, \quad 22- \\
28,30-37\end{array} \\
\end{array}$ \\
\hline 13 & Alcoholic and soft drinks & 15.9 & 13 & Utilities & 40,41 \\
\hline 14 & Wood and paper products (except furniture) & $20,21.1,21.2$ & 14 & Construction & 45 \\
\hline 15 & Machinery & 29 & 15 & Wholesale and retail trade & $50-52$ \\
\hline 16 & Other manufacturing & $16-19,22-28,30-37$ & 16 & Hotels and restaurants & 55 \\
\hline 17 & Utilities & 40,41 & 17 & Transport and communications & $60-64$ \\
\hline 18 & Construction & 45 & 18 & Financial services & $65-67$ \\
\hline 19 & Wholesale and retail trade & $50-52$ & 19 & Public service activities & $75-90$ \\
\hline 20 & Hotels and restaurants & 55 & 20 & Other services & $\begin{array}{l}\begin{array}{l}70-74, \\
95\end{array} \\
\end{array}$ \\
\hline 21 & Transport and communications & $60-64$ & & & \\
\hline 22 & Financial services & $65-67$ & & & \\
\hline 23 & Public service activities & $75-90$ & & & \\
\hline 24 & Other services & $70-74,91-95$ & & & \\
\hline
\end{tabular}




\section{Appendix B. Policy simulation}

For Aberdeen City and Aberdeenshire, information on Rural Development Programme expenditure in the region was gathered from the Scottish Government website and interviews with the local Scottish Government Rural Inspections and Payments Directorate (SGRIPD) representative and the Rural Development Officer in Aberdeenshire Council. Total Pillar 2 payments are calculated (Table 1) using a combination of actual and total planned annual expenditure for the period 2005-2013, with the Aberdeen and Aberdeenshire share calculated on the proportion of total RDP funds which has been spent in the area. It is assumed that the average expenditure in the 2007-2013 period is maintained to 2020. The share of spending undertaken by measure is calculated using the proportions in each measure in actual spending provided by the Scottish Government. LEADER expenditure is directly incorporated in the calculations.

Detailed information regarding all financed projects (especially total costs and private costs) has been provided by the Local Action Group (LAG) Rural Aberdeenshire. Similarly, the private contributions in Axis 1 and 3 are taken into account. Further, modulation in Scotland includes a voluntary component and these flows between Pillar 1 and 2 are incorporated in the Baseline. Following the Health Check agreement, the total modulation rates (compulsory and voluntary) in Scotland are calculated as shown below. If the compulsory modulation rate is $10 \%$ and the additional voluntary rate is $4 \%$ in 2012 , the total modulation rate is equal to $14 \%$ for the same year. The proportion of modulation funds attributed to each Axis is calculated using the base-period proportion of Pillar 2 funds going to the concerned Axis.

Table B1. Pillar 2 expenditure in Aberdeen City and Aberdeenshire, 2007-2013 programming period (total cost, ml. GBP)

\begin{tabular}{lllll}
\hline Measures, Pillar 2 & Axis 4 & Total cost & $\begin{array}{l}\text { \% } \\
\text { in Pillar 2 }\end{array}$ \\
\hline 111 & Vocational training & - & 0.04 & 0.0 \\
\hline 112 & Setting up young farmers & - & 0.58 & 0.3 \\
\hline 114 & Use of advisory services & - & 0.00 & 0.0 \\
\hline 121 & Modernization of agricultural holdings & - & 54.35 & 27.0 \\
\hline 122 & Improvement of the economic value of forests & - & 0.59 & 0.3 \\
\hline 123 & Adding value to agricultural and forestry products & - & 0.96 & 0.5 \\
\hline 125 & Infrastructure related to the development and & - & 0.11 & 0.1 \\
& adaptation of agriculture and forestry & & & \\
\hline Total & Axis 1 & - & $\mathbf{5 6 . 6 4}$ & $\mathbf{2 8 . 1}$ \\
\hline 214 & Agri-environment payments & - & 81.29 & 40.3 \\
\hline 223 & First afforestation of non-agricultural land & - & 16.37 & 8.1 \\
\hline 225 & Forest-environment payments & - & 2.42 & 1.2 \\
\hline 227 & Nonproductive investments & - & 0.75 & 0.4 \\
\hline Total & Axis 2 & - & $\mathbf{1 0 0 . 8 3}$ & $\mathbf{5 0 . 0}$ \\
\hline 311 & Diversification into non-agricultural activities & - & 14.14 & 7.0 \\
\hline 312 & Support for business creation and development & 1.16 & 6.88 & 3.4 \\
\hline 313 & Encouragement of tourism activities & 1.34 & 4.10 & 2.0 \\
\hline
\end{tabular}




\begin{tabular}{lllll}
\hline 321 & $\begin{array}{l}\text { Basic services for the economy and rural } \\
\text { population }\end{array}$ & 2.05 & 10.05 & 5.0 \\
\hline 323 & Conservation and upgrading of the rural heritage & 1.87 & 5.36 & 2.7 \\
\hline 331 & Training and information & 1.26 & 3.53 & 1.7 \\
\hline 341 & $\begin{array}{l}\text { Skills-acquisition and animation measure with a } \\
\text { view to preparing and implementing a local }\end{array}$ & & 0.15 & 0.1 \\
$\quad$ development strategy & & & \\
\hline $\begin{array}{l}\text { Total Axis 3 } \\
\text { Total Pillar 2 }\end{array}$ & $\mathbf{7 . 7 3}$ & $\mathbf{4 4 . 2 1}$ & $\mathbf{2 1 . 9}$ \\
\hline
\end{tabular}

Source: Scottish Government; DEFRA; Authors' calculations.

Table 1 shows that Axis 1 represents approximately $28 \%$ of total Pillar 2 expenditure, Axis $250 \%$ and Axis $322 \%$. The most important measures in terms of expenditure are $214(40.3 \%$ of total Pillar 2), $121(27 \%), 223$ (8.1\%), and among Axis 3 measures, $311(7 \%), 321(5 \%)$ and 312 (3.4\%). Axis 1 expenditure is assumed to either add to capital investment either in agriculture or forestry (Measure 122). These flows are allocated to various agricultural and forestry sectors on the basis of their shares in the model base-year capital. The detailed practical implementation of modelling Pillar 2 is presented in Table D3 at the end of this Appendix.

There is very little information related to allocating Axis 3 expenditure to the SAM sectors as the Scottish Government does not collect information identifying the destination of RDP spending by sector. Therefore in order to do this, a number of ultimately arbitrary assumptions are required and are summarised in Table 2. For each Axis 3 measure, we assume which sectors might benefit based on the informal information we have, e.g. discussion with the local RDP coordinator. Hence, for example, Measure Axis 311 expenditure is assumed to benefit rural forestry, energy and hotels, 312 rural energy and hotels, 313 rural hotels only. It is assumed that spending in Measures 321-341 is allocated to the rural public sector and other services.

Table B2. Sectors benefitting from Axis 3 investment, Aberdeen City and Shire

\begin{tabular}{lccccccc}
\hline & 311 & 312 & 313 & 321 & 323 & 331 & 341 \\
\hline R-Forestry & $10 \%$ & & & & & & \\
R-Energy & $40 \%$ & $20 \%$ & & & & & \\
R-Hotels & $50 \%$ & $80 \%$ & $100 \%$ & & & & \\
R-Public & & & & $100 \%$ & $100 \%$ & & \\
R-Other Services & & & & & & $100 \%$ & $100 \%$ \\
\hline
\end{tabular}

Source: Authors' calculations.

The main mechanism used to implement the policy change in the model has been to focus on the assumed induced changes in investment, as in Psaltopoulos et al. (2011), but also on capital stock within key industries. This approach is motivated by the fact it accommodates the fact that RDP investment projects (and their economic effects) are generally specific to a time-path and in parallel, generates a dynamic capital stock adjustment amongst different activities. For exogenous sectors (i.e., those targeted by policy measures), the growth rate of capital stock is set and the amount of investment required for this sector is calculated. These values are then taken from the total amount of investment available for allocation to endogenous sectors. In endogenous sectors (i.e., those not targeted by policy measures), allocation of new capital uses a partial adjustment 
mechanism, with those activities where returns are higher than average obtaining a higher than average share of the available new capital; new capital is determined by the total investment in commodities (minus the amount required for exogenous sectors).

This approach requires assumptions on the commodity composition of new capital, the economic mechanism at work, i.e., RDP policy inducing extra investment in a sector, can be closely followed in the model, whereas the specific link between say a particular investment and a change in efficiency is much more difficult to specify due to the lack of relevant data. We therefore need to map RDP spending in the region into investments in specific SAM sectors within the models. Data availability and the way the Rural Development Programme has been implemented and interpreted vary considerably in the EU. In fact, in Scotland, regions set rural priorities and total funding is allocated via "Options" which do not map simply into the RDP measures. Hence, the supplementary assumptions required to implement this approach are specific to the region-study of Aberdeen. Further, at least for the time being, the government has not disaggregated the RDP spend by measure at the case study area level (with the exception of Axis 4 - Leader), nor does it collect information identifying the destination of RDP spending by sector. In order to circumvent this, we assume sectoral allocation of RDP spend from discussions with RDP and LEADER local implementing agencies.

Once the assumed allocation of RDP spend to specific sectors has been made, the various simulations are constructed in a series of steps. First, the model is run with all sectors treated as endogenous. This defines the growth rate without RDP spend in the sectors which are assumed to benefit from RDP spending. The growth rate in capital stock in these sectors is calculated after the RDP spend is added and then the model is re-run with these capital growth rates set exogenously. In addition, to account for extra subsidy inflows to the region, the foreign savings inflow is increased by the amount of the RDP spend which is assumed to be funded by EU and/or national government and/or private funds. We consider the total subsidy from both national and EU sources as if it comes from outside the region (with any private sector part funded from within the region). Finally, to allow for possible changes in ownership of factor income as results of the RDP policy, the model has been adjusted to allow for differing patterns of factor ownership by sector. Hence, where new investments associated with the RDP spend are thought to significantly change factor ownership patterns, the effect of this has been explored (e.g. farm diversification investment in various sectors). Investment-driven savings (with overall investment increased to allow for extra RDP investment) plus exogenous foreign savings are used as closure rules in the base run. This ensures that extra economic activity due to the extra RDP investment and subsidy inflows is not conflated with changes in investment due to changes in savings behaviour in aggregate and/or inflows from other sources. 
Table B3. Modelling Pillar 2 Measures in Aberdeenshire and City

\begin{tabular}{|c|c|c|c|c|}
\hline Measures & Title & $\begin{array}{l}\text { Sectors Benefiting } \\
\text { from Investment }\end{array}$ & $\begin{array}{l}\text { Ownership of } \\
\text { New } \\
\text { Investment }\end{array}$ & Other Type of Shock \\
\hline \multicolumn{5}{|l|}{ Axis 1} \\
\hline 111 & Vocational training & Agricultural sub- & Small & \\
\hline 112 & Setting up young farmers & sectors. Allocation of & Large & \\
\hline 114 & Use of advisory services & investment flows on & households. & \\
\hline 121 & $\begin{array}{l}\text { Modernization of agricultural } \\
\text { holdings }\end{array}$ & $\begin{array}{l}\text { the basis of their } \\
\text { shares in base year } \\
\text { farm output. }\end{array}$ & & \\
\hline 122 & $\begin{array}{l}\text { Improvement of the economic } \\
\text { value of forests }\end{array}$ & Forestry & & \\
\hline 123 & $\begin{array}{l}\text { Adding value to agricultural } \\
\text { and forestry products }\end{array}$ & $\begin{array}{l}\text { Agricultural sub- } \\
\text { sectors. Allocation of }\end{array}$ & & \\
\hline 125 & $\begin{array}{l}\text { Infrastructure related to the } \\
\text { development and adaptation of } \\
\text { agriculture and forestry }\end{array}$ & $\begin{array}{l}\text { investment flows on } \\
\text { the basis of their } \\
\text { shares in base year } \\
\text { farm output. }\end{array}$ & & \\
\hline \multicolumn{5}{|l|}{ Axis 2} \\
\hline 214 & Agri-environment payments & & $\begin{array}{l}\text { Small and } \\
\text { Large farm } \\
\text { households. }\end{array}$ & $\begin{array}{l}\text { Coupled payment to } \\
\text { agricultural sub-sectors. } \\
\text { Allocation of } \\
\text { investment flows on the } \\
\text { basis of their shares in } \\
\text { base year farm output. }\end{array}$ \\
\hline 223 & $\begin{array}{l}\text { First afforestation of non- } \\
\text { agricultural land }\end{array}$ & Forestry & & \\
\hline 225 & Forest-environment payments & & & \\
\hline 227 & Non-productive investments & & & $\begin{array}{l}\text { Coupled payment to } \\
\text { agricultural sub-sectors. } \\
\text { Allocation of } \\
\text { investment flows on the } \\
\text { basis of their shares in } \\
\text { base year farm output. }\end{array}$ \\
\hline \multicolumn{5}{|l|}{ Axis 3} \\
\hline 311 & $\begin{array}{l}\text { Diversification into non- } \\
\text { agricultural activities }\end{array}$ & $\begin{array}{l}\text { Rural Energy, Rural } \\
\text { Hotels \& Restaurants } \\
\text { Forestry }\end{array}$ & $\begin{array}{l}\text { Small \& Large } \\
\text { farm } \\
\text { households. }\end{array}$ & \\
\hline 312 & $\begin{array}{l}\text { Support for business creation } \\
\text { and development }\end{array}$ & $\begin{array}{l}\text { Rural Energy, Rural } \\
\text { Hotels \& Restaurants }\end{array}$ & $\begin{array}{l}\text { Rural, Urban, } \\
\text { Small \& Large } \\
\text { farm } \\
\text { households. }\end{array}$ & \\
\hline 313 & $\begin{array}{l}\text { Encouragement of tourism } \\
\text { activities }\end{array}$ & Hotels \& Restaurants & $\begin{array}{l}\text { Rural, Urban, } \\
\text { Small \& Large } \\
\text { farm } \\
\text { households. }\end{array}$ & \\
\hline 321 & $\begin{array}{l}\text { Basic services for the } \\
\text { economy and rural population }\end{array}$ & & & $\begin{array}{l}\text { Exogenous Increase in } \\
\text { Investment Commodity }\end{array}$ \\
\hline 323 & $\begin{array}{l}\text { Conservation/upgrading of the } \\
\text { rural heritage }\end{array}$ & & & $\begin{array}{lr}\text { Demand } & \text { without } \\
\text { adding to } & \text { productive }\end{array}$ \\
\hline 331 & Training and information & & & capital stock. \\
\hline 341 & Skills-acquisition & & & \\
\hline
\end{tabular}




\section{Appendix C. Identification of key elasticities}

Table C1. Identification of elasticities in the CGE model

\begin{tabular}{lll}
\hline Elasticity type & $\begin{array}{l}\text { Kolmogorov- } \\
\text { Smirnov test } \\
p \text {-value }\end{array}$ & Influence of elasticity \\
\hline Armington & & \\
Crops & 0.000 & critical \\
Livestock & 0.000 & critical \\
Forestry & 0.046 & important \\
Fish & 0.059 & important \\
Oil & 0.077 & important \\
Food processing & 0.005 & critical \\
Other food industries & 0.003 & critical \\
Financial services & 0.007 & critical \\
Public services & 0.001 & critical \\
Other services & 0.013 & important \\
Transformation & & \\
Crops & 0.000 & critical \\
Forestry & 0.020 & important \\
Fish & 0.071 & important \\
Other food industries & 0.058 & important \\
Drink & 0.044 & important \\
Machinery & 0.001 & critical \\
Other manufacturing & 0.018 & important \\
Energy & 0.037 & important \\
Hotels & 0.001 & critical \\
Transports & 0.008 & critical \\
Pubic services & 0.057 & important \\
\hline
\end{tabular}

Substitution between production factors and intermediate inputs (PRODUCTION)

U-Large Cereal farms $\quad 0.013$

U-Large Livestock farms $\quad 0.093$

U-Small Livestock farms $\quad 0.022$

U-Large Other farms $\quad 0.027$

U-Small Other farms $\quad 0.019$

U-Oil

0.025

U-Mining

0.005

U-Food processing $\quad 0.018$

U-Other food industries $\quad 0.094$

U-Drink

0.073

U-Wood

U-Financial services

0.018

0.073

0.022

U-Public services

0.001

R-Small Livestock farms

0.090 important important important important important important critical important important important important important important critical important 


\begin{tabular}{lll} 
R-Large Other farms & 0.000 & critical \\
R-Small Other farms & 0.092 & important \\
R-Forestry & 0.037 & important \\
R-Mining & 0.068 & important \\
R-Wood & 0.015 & important \\
R-Machinery & 0.071 & important \\
R-Construction & 0.063 & important \\
R-Hotels & 0.003 & critical \\
Substitution between production factors $(S U B S T I T U T I O N)$ & \\
U-Large Cereal farms & 0.016 & important \\
U-Large Livestock farms & 0.093 & important \\
U-Small Livestock farms & 0.022 & important \\
U-Large Other farms & 0.023 & important \\
U-Small Other farms & 0.013 & important \\
U-Oil & 0.021 & important \\
U-Mining & 0.006 & critical \\
U-Food processing & 0.015 & important \\
U-Other food industries & 0.081 & important \\
U-Drink & 0.073 & important \\
U-Wood & 0.015 & important \\
U-Financial services & 0.063 & important \\
U-Public services & 0.022 & important \\
R-Large Cereal farms & 0.001 & critical \\
R-Large Other farms & 0.000 & critical \\
R-Small Other farms & 0.079 & important \\
R-Forestry & 0.043 & important \\
R-Mining & 0.058 & important \\
R-Wood & 0.015 & important \\
R-Machinery & 0.083 & important \\
R-Construction & 0.074 & important \\
R-Hotels & 0.044 & \\
\hline important \\
\hline
\end{tabular}

Note: U and R stand respectively for Urban and Rural 
Table C2. Most important elasticities in the CGE model, alternative closure rule

\begin{tabular}{|c|c|c|}
\hline Elasticity type & $p$-value & Influence of elasticity \\
\hline \multicolumn{3}{|l|}{ Armington } \\
\hline Crops & 0.001 & critical \\
\hline Food processing & 0.006 & critical \\
\hline Wood & 0.003 & critical \\
\hline Other Manufacturing & 0.000 & critical \\
\hline Distribution & 0.005 & critical \\
\hline Financial services & 0.000 & critical \\
\hline \multicolumn{3}{|l|}{ Transformation } \\
\hline Forestry & 0.003 & critical \\
\hline Other Food & 0.000 & critical \\
\hline Wood & 0.002 & critical \\
\hline Machinery & 0.009 & critical \\
\hline Other Manufacturing & 0.001 & critical \\
\hline Construction & 0.001 & critical \\
\hline Distribution & 0.001 & critical \\
\hline Transport & 0.001 & critical \\
\hline \multicolumn{3}{|c|}{ Substitution between production factors and intermediate inputs } \\
\hline U-Large Cereal Farms & 0.000 & critical \\
\hline U-Small Other Farms & 0.004 & critical \\
\hline U-Fish & 0.002 & critical \\
\hline U-Oil & 0.001 & critical \\
\hline U-Drink & 0.005 & critical \\
\hline U-Wood & 0.000 & critical \\
\hline U-Other Manufacturing & 0.002 & critical \\
\hline U-Energy & 0.006 & critical \\
\hline U-Transport & 0.000 & critical \\
\hline U-Public services & 0.001 & critical \\
\hline U-Other Services & 0.002 & critical \\
\hline R-Large Cereal Farms & 0.000 & critical \\
\hline R-Small Cereal Farms & 0.001 & critical \\
\hline R-Large Livestock Farms & 0.001 & critical \\
\hline R-Fish & 0.000 & critical \\
\hline R-Oil & 0.004 & critical \\
\hline R-Wood & 0.000 & critical \\
\hline R-Other Manufacturing & 0.007 & critical \\
\hline R-Transport & 0.005 & critical \\
\hline \multicolumn{3}{|c|}{ Substitution between production factors } \\
\hline U-Large Cereal Farms & 0.000 & critical \\
\hline U-Small Other Farms & 0.002 & critical \\
\hline U-Fish & 0.002 & critical \\
\hline U-Oil & 0.001 & critical \\
\hline U-Drink & 0.003 & critical \\
\hline
\end{tabular}




$\begin{array}{lll}\text { U-Other Manufacturing } & 0.002 & \text { critical } \\ \text { U-Transport } & 0.000 & \text { critical } \\ \text { U-Other Services } & 0.001 & \text { critical } \\ \text { R-Large Cereal Farms } & 0.000 & \text { critical } \\ \text { critical } \\ \text { R-Small Cereal Farms } & 0.001 & \text { critical } \\ \text { R-Large Livestock Farms } & 0.001 & \text { critical } \\ \text { R-Fish } & 0.000 & \text { critical } \\ \text { R-Oil } & 0.004 & \text { critical } \\ \text { R-Wood } & 0.000 & \text { critical } \\ \text { R-Other Manufacturing } & 0.008 & \text { critical } \\ \text { R-Hotels } & 0.001 & \text { critical } \\ \text { R-Trans } & 0.005 & \text { critical } \\ \text { R-Other Services } & 0.000 & \end{array}$

Note: $\mathrm{U}$ and $\mathrm{R}$ stand respectively for Urban and Rural

\section{References}

Flegg, A. T. and T. Tohmo (2013) Regional input-output tables and the FLQ formula: A case study of Finland. Regional Studies, 47, 703-721.

General Register Office for Scotland (2013) 2001 Census. http://www.groscotland.gov.uk/census/censushm/ . Accessed May 2013

Mary, S., E. Phimister, D. Roberts and F. Santini (2013) Testing the sensitivity of CGE models: a Monte Carlo filtering approach to rural development policies in Aberdeenshire. JRC Scientific and Policy Reports, European Commission. Available at ftp://jrc.es/pub/EURdoc/JRC85290.pdf

NOMIS (2009) Annual Business Inquiry. https://www.nomisweb.co.uk/Default.asp Accessed March 2010.

Office for National Statistics (2006) Annual Survey of Hours and Earnings (ASHE) http://www.statistics.gov.uk/statbase/product.asp?vlnk=13101, Accessed March 2010.

Office for National Statistics (2007) Family Spending 2005/06. Office for National Statistics. http://www.statistics.gov.uk/statbase/ Accessed March 2010.

Scottish Enterprise (2009) Aberdeen City and Shire Economic Review. SLIMS and Oxford Economics. March 2009.

Scottish Government (2013) Scottish Government Input Output Tables. http://www.scotland.gov.uk/Topics/Statistics/Browse/Economy/Input-Output. Accessed May 2013. 